\title{
The application of the metal organic framework for ion removal in seawater
}

\author{
Jindrayani Nyoo Putro ${ }^{\mathrm{a}, *}$, Immanuel Joseph Ondang ${ }^{a}$, Valentino Bervia Lunardi ${ }^{\mathrm{a}}$, Suryadi Ismadji a,b, \\ Felycia Edi Soetaredjo a,b ${ }^{\mathrm{a}}$, Adriana Anteng Anggorowati ${ }^{\mathrm{a}}$, Shella Permatasari Santoso ${ }^{\mathrm{a}, \mathrm{b}}$, Jenni Lie ${ }^{\mathrm{b}}$, \\ Chintya Gunarto ${ }^{\mathrm{b}}$
}

${ }^{a}$ Department of Chemical Engineering, Widya Mandala Surabaya Catholic University, Kalijudan 37, Surabaya 60114, Indonesia

${ }^{\mathrm{b}}$ Department of Chemical Engineering, National Taiwan University of Science and Technology No. 43, Section 4, Keelung Rd, Da'an District, Taipei City 10607, Taiwan

\section{A R T I C L E I N F O}

\section{Article history:}

Received 15 February 2021

Revised 5 April 2021

Accepted 8 April 2021

Available online 20 April 2021

\begin{abstract}
A B S T R A C T
Metal-Organic Framework (MOF) was used as an adsorbent in the desalination process. In this study, MIL-53 Al was employed to remove ions from seawater. MIL-53 was prepared using $\mathrm{Al}\left(\mathrm{NO}_{3}\right)_{3} \cdot 9 \mathrm{H}_{2} \mathrm{O}$ as a precursor, which dissolved with ethanol-water, then ligand was added by the ratio of metal to ligands $1: 1.5$. The crystallography of MIL-53(Al) was investigated using X-ray diffraction analysis to obtain a clear structure of crystals before and after activation. MIL-53(Al)(ht) 's adsorption ability was tested for ions adsorption from seawater at $303 \mathrm{~K}$. The removal efficiency of MIL-53(Al)(ht) toward multi-ion was $20.5 \%$ with an adsorption capacity of $147.7 \mathrm{mg}$ ions/g MIL-53. The ions adsorption removal in MIL-53 (Al)(ht) follow the sequence of $\mathrm{Cl}^{+}>\mathrm{Na}^{+}>\mathrm{SO}_{4}^{2+}>\mathrm{Mg}^{2+}>\mathrm{K}^{+}>\mathrm{Ca}^{2+}$. The reusability of MIL-53(Al)(ht) was also investigated, and the result indicated that its adsorption capacity significantly decreased after the 1st cycle of adsorption/desorption.
\end{abstract}

(c) 2021 Elsevier B.V. All rights reserved.

\section{Introduction}

Water is an essential component in human life; humans need clean water in sufficient quantities. Even though the earth has a sustained amount of water; however, $93 \%$ of it is saline water. Currently, the availability of clean water decreases due to excessive environmental pollution and global warming. Water scarcity becomes a common problem in most underdeveloped and developing countries. The very rapid development of industrialization in these countries has also greatly affected clean water sources. The utilization of seawater is one way to deal with the scarcity of clean water [1].

Numerous desalination studies have been conducted to process saline water into freshwaters, such as reverse osmosis, multi-stage flash, multi-effect distillation, and adsorption desalination [2]. These technologies are expensive, high energy-intensive, and prone to severe corrosion and fouling [3,4]. Another method, such as adsorption, can be an alternative technique due to its effectiveness and economic point of view. Several investigations have been conducted to decrease salinity and soften hard water from drainage water and groundwater using adsorbents like zeolite, carbon

\footnotetext{
* Corresponding author.

E-mail address: jindranyoo@yahoo.com (J.N. Putro).
}

nanotubes, activated carbon, graphenes, bio-sorbent, and industrial by-products [5-12].

Due to its excellent chemical characteristics, metal-organic framework (MOF) has been widely studied for various applications, such as capturing $\mathrm{CO}_{2}$ gas, adsorption of heavy metal and dyes, desalination, water harvesting, methane storage, and photocatalytic antibacterial activity [13-19]. MOF has porous and high surface area characteristics; the pore size and geometry can be tuned based on the ligand and metal content. For the desalination purpose, various MOF varieties such as Aluminium-Fumarate, UiO66, CPO-21, and MIL-101, MIL-53 have been intensively studied to adsorb water from saline water [20-22]. A study showed that Aluminum Fumarate gave better water adsorption than silica gel, and the water adsorption performance increased with increasing temperatures [20]. In the adsorption - desalination process, the functional groups of MOF (UiO-66(Zr)) also played a significant role in the water uptake, as demonstrated by Han and Chakraborty [21]. The presence of the functional groups on the structure of MOF significantly improves water transfer.

The main obstacle of using adsorption - desalination process for desalination is the use of energy for water evaporation. Therefore, direct removal of ions from seawater using the adsorption process to obtain freshwater is preferable since the process is energysaving and the adsorbent can be regenerated. The strategy applied in this study is to select an adsorbent that can adsorb ions from 
seawater and regenerate easily to meet these objectives. Currently, only a few studies were conducted to explore the feasibility of using the adsorption method for the desalination process [2324], and most of them used sodium chloride solution as the seawater.

In this study, we directly employed aluminum-based MOF (MIL-53(Al)) as the adsorbent for direct adsorption of ions from seawater. The advantages of using aluminum-based MOFs compared to other metals: they are more stable since it is inert towards redox reactions at specific conditions and relatively abundant compared to other metals [25]. Up to this date, MIL-53 ( $\mathrm{Al}$ ) is generally used for adsorption desalination and mostly did not give significant results due to its low water uptake [26]. To the best of our knowledge, there is no study performed using MIL-53 (Al) to remove ions from seawater. Hence, this study aims to investigate the removal of ions from seawater using MIL-53 (Al).

\section{Materials and methods}

\subsection{Materials}

Aluminum nitrate nonahydrate $\left(\mathrm{Al}\left(\mathrm{NO}_{3}\right)_{3} \cdot 9 \mathrm{H}_{2} \mathrm{O}\right)$, benzene dicarboxylic acid acid/BDC $\left(\mathrm{C}_{6} \mathrm{H}_{4}-1,4-\left(\mathrm{CO}_{2} \mathrm{H}\right)_{2}\right)$, ethanol $\left(\mathrm{C}_{2} \mathrm{H}_{6} \mathrm{O}\right.$ : $>99 \%)$, silver nitrate $\left(\mathrm{AgNO}_{3}: \geq 99.0 \%\right)$, potassium chromate $\left(\mathrm{K}_{2} \mathrm{CrO}_{4}: \geq 99.0 \%\right)$, barium chloride $\left(\mathrm{BaCl}_{2}: 99.9 \%\right)$, hydrochloric acid ( $\mathrm{HCl}: 37 \%)$, phenolphthalein $\left(\mathrm{C}_{20} \mathrm{H}_{14} \mathrm{O}_{4}\right.$ : ACS reagent), sodium chloride ( $\mathrm{NaCl}: \geq 99.0 \%)$, sodium sulfate $\left(\mathrm{Na}_{2} \mathrm{SO}_{4}: \geq 99.0 \%\right)$ were procured from Sigma Aldrich. Tetrahydroxy-1,4-benzoquinone disodium salt $\left(\mathrm{C}_{6} \mathrm{H}_{2} \mathrm{Na}_{2} \mathrm{O}_{6}\right.$ : TCI America) was purchased from Fisher Scientific. Seawater was collected from Balekambang beach, Malang, East Java, Indonesia.

\subsection{Preparation MIL-53}

The preparation of MIL-53 was conducted hydrothermally with a brief procedure as follow: $\mathrm{Al}\left(\mathrm{NO}_{3}\right)_{3} \cdot 9 \mathrm{H}_{2} \mathrm{O}$ and $\mathrm{BDC}$ with the mole ratio of 1:1.5 were dissolved in the total volume of $60 \mathrm{~mL}$ ethanol and water with a volume ratio of 1 to 1 ; the mixture is then poured into Teflon lined reactor and heated for $48 \mathrm{~h}$ at $453 \mathrm{~K}$. White powder was filtered against filter paper and washed with ethanol, then dried at $373 \mathrm{~K}$ for $6 \mathrm{~h}$. Up to this point, MIL-53 is called MIL-53(Al) (as) or MIL-53(Al) as synthesized. After drying, the powder was further activated at $603 \mathrm{~K}$ for $12 \mathrm{~h}$, coded with MIL-53(Al)(ht) or MIL-53(Al) high temperature.

\subsection{Characterization}

The crystal morphology was observed with the scanning electron microscope (FESEM JEOL JSM-6500F). The $\mathrm{N}_{2}$ adsorption and desorption profiles of materials were obtained by Belsorp mini (Bel Japan) at $77 \mathrm{~K}$; the samples were degassed before analysis at $423 \mathrm{~K}$ for $4 \mathrm{~h}$. The specific surface area was calculated using the BET method, and the pore distribution was measured with the BJH equation. X-ray diffraction analysis was conducted using Bruker D2 Phaser operating with Ni-filtered $\mathrm{Cu} \mathrm{K} \alpha$ radiation $(\lambda=0.1541 \mathrm{~nm})$ and a $2 \theta$ range of $5-40^{\circ}$, step size of $0.025^{\circ}$. Crystal structures for MIL-53(Al) were determined using the method of Treor90 with software MATCH version 3.0. The average particle size of crystal was calculated from the width of the diffraction peaks using the following Scherrer equation [27]:

$D=\frac{\kappa \lambda}{\beta \cos \theta}$

where $D$ is the mean crystal size perpendicular to the reflecting planes $(\mathrm{nm}), \lambda$ is the $\mathrm{x}$-ray wavelength $(\mathrm{nm}), \kappa$ is shape factor constant in the range $0.8-1.2$ (typically equal to 0.94 ), $\beta$ is the width peak based on full width at half maximum (rad), and $\theta$ is Bragg angle (rad).

\subsection{Analysis of the composition of seawater}

Seawater was centrifuged to separate any impurities before further analysis, then subjected to Mohr's method titration to quantify the anion $\mathrm{Cl}^{-}$. The anion sulfate was obtained using a direct titration with the indicator of THQ [28]. The analysis of cation $\mathrm{Na}^{+}, \mathrm{K}^{+}, \mathrm{Mg}^{2+}$, and $\mathrm{Ca}^{2+}$ was carried on using atomic absorption spectroscopy (Shimadzu AA 6200) at wavelength $589.5 \mathrm{~nm}$, $766.5 \mathrm{~nm}, 285.2 \mathrm{~nm}$, and $422.7 \mathrm{~nm}$, respectively. All measurements were repeated triplicate.

\subsection{Ions removal}

The ions removal from seawater was conducted using several stages of adsorption processes. The first stage process' effluent, becomes the influent of the subsequent stage, and each stage of adsorption was run for 3 hours. Adsorption of ions was carried out in a $30 \mathrm{~mL}$ centrifuge tube at $303 \mathrm{~K}, 0.5 \mathrm{~g}$ of MIL-53(Al) was added into the tube contained $10 \mathrm{~mL}$ of seawater. The concentration of ions for the adsorption stage and the efficiency of adsorbent reusability are calculated by the following equations:

Ion removal $(\mathrm{mg} / \mathrm{g})=\frac{\left(C_{n-1}-C_{n}\right) V}{m}$

Removal efficiency $(\%)=\frac{C_{o}-C_{n}}{C_{o}} \times 100$

$C_{o}$ is the initial concentration of ion $(\mathrm{mg} / \mathrm{L})$, and $C_{n}$ is the equilibrium concentration at stage $\mathrm{n}(\mathrm{mg} / \mathrm{L}) . V$ and $m$ stand for volume (L) and mass ( $\mathrm{g}$ ), respectively. The removal efficiency was calculated cumulatively to the initial concentration of each ion.

The adsorbent's regeneration was investigated as follows: $0.3 \mathrm{~g}$ adsorbent was immersed in seawater for $24 \mathrm{~h}$ at $303 \mathrm{~K}$, the adsorbent was separated from the solution using the centrifugation technique and dried at $323 \mathrm{~K}$ overnight. The concentration of ions in the solution was determined according to the methods that were previously described. The adsorbent was then immersed in $10 \mathrm{~mL}$ of pure water for $24 \mathrm{~h}$, and this step is considered the adsorption-desorption cycle. The experiments were carried out in triplicate. The percent of ions desorbed from MIL-53 ( $\mathrm{Al}$ ) (ht) is calculated by the following equation:

Desorption $(\%)=\frac{C_{\text {initial loading }}-C_{\text {ion release }}}{C_{\text {initial loading }}} V \times 100$

\section{Results \& discussions}

\subsection{Characterization of MIL-53(Al)(as) and MIL-53(Al)(ht)}

The topography of MIL-53(Al)(as) is depicted in Fig. 1(a). As seen in this figure, MIL-53( $\mathrm{Al})(\mathrm{as})$ is a long rod-like block shape and has a $185.6 \pm 4.9 \mathrm{~nm}$ structure width. The formation of this crystal structure is strongly affected by water as a solvent [29]. After activation, the morphology of MIL-53(Al)(ht) utterly different from MIL-53(Al)(as). Smaller and agglomerated particles were observed after the high-temperature activation (Fig. 1(b)).

The diffraction results of MIL-53(Al) before and after activation are depicted in Fig. 1(c). MIL-53(as) has a large pore characteristic with a distinct peak at $2 \theta=8.6^{\circ}$ [30]. MIL-53 (Al) has peculiar property; it can "breathe" with water molecules inside the crystal structure framework. The choice of alcohol and water mixture as 

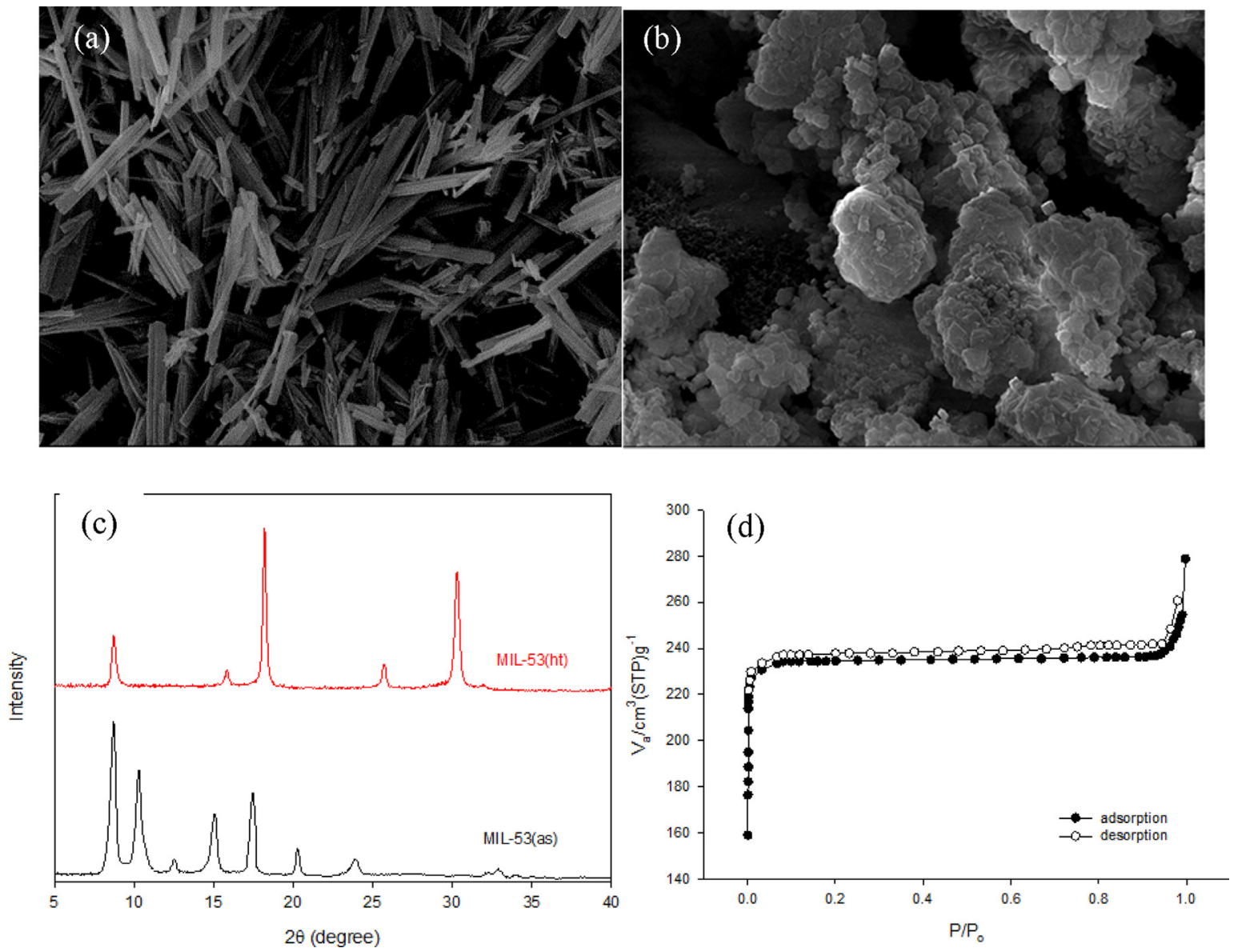

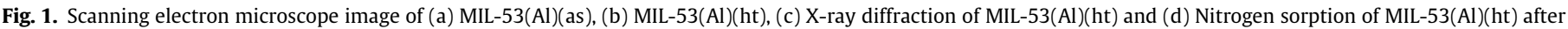
its activation.

the solvent system investigates the effect of the hydroxyl group of ethanol in the MIL-53 ( $\mathrm{Al})$ network. Himsl and the co-author explained that water must be present in the solvent system of MIL-53 Al to incorporate hydroxyl ions that connect $\mathrm{AlO}_{6}$ octahedra into infinite chains [29]. A large pore of MIL-53(Al) is formed due to the water and ethanol affecting the Aluminum crystal framework growth. The diffraction peak of MIL-53(as) is similar to that obtained by Mounfield and Walton [31]. MIL-53(Al)(as) has two close peaks at $8.7^{\circ}$ and $10.3^{\circ}$. The XRD analysis shows that MIL-53(Al) prior annealing has triclinic crystal lattice (obtained from the crystal structure simulation using Match 3). After calcination, several peaks belonging to ligand BDC were removed entirely; the remaining characteristic peak of MIL-53(Al)(ht) indicates the transition of crystal structure change at $2 \theta$ of $15.8^{\circ}$ and $18.1^{\circ}$. After activation, the large pore of MIL-53(Al) diffraction peak is retained at $2 \theta$ of $8.7^{\circ}$.

The reaction mechanism for MOF formation is complex; for example, crystal MIL-53(Al) growth depends on the reaction condition, including the solvent, ligand, and temperature [32]. For the case of MIL-53(Sc), a temperature up to $473 \mathrm{~K}$ resulted in a monoclinic structure [33]. The results of the crystal structure simulation for MIL-53(Al)(as) and MIL-53(Al)(ht) are tabulated in Table 1. Based on Scherrer's equation, the average crystalline size of MIL$53(\mathrm{Al})(\mathrm{as})$ and MIL-53( $\mathrm{Al})(\mathrm{ht})$ are $24.8 \mathrm{~nm}$ and $29.4 \mathrm{~nm}$, respectively. The difference in particle size confirms the breathing behavior of MIL-53(Al), a more significant crystalline domain of MIL-53 (Al)(ht) than MIL-53(Al)(as) due to the expansion of pore after losing the hydration effect [34].
Table 1

Unit cell parameter of MIL-53.

\begin{tabular}{lll}
\hline Material & MIL-53(Al)(as) & MIL-53(Al)(ht) \\
\hline Crystal system & Triclinic & Orthorhombic \\
a & $9.9 \AA$ & $17.4 \AA$ \\
b & $11.8 \AA$ & $8.6 \AA$ \\
c & $19.1 \AA$ & $5.9 \AA$ \\
$\alpha$ & $62.6^{\circ}$ & $90^{\circ}$ \\
$\beta$ & $49.5^{\circ}$ & $90^{\circ}$ \\
$\gamma$ & $97.6^{\circ}$ & $90^{\circ}$ \\
\hline
\end{tabular}

The nitrogen sorption of MIL-53(Al)(ht) is depicted in Fig. 1(c), which indicates type 1 adsorption isotherm. This isotherm shows a typical microporous and mesoporous MIL-53(Al)(ht) characteristic with high pore volume. MIL-53(Al)(ht) has a specific surface area of $791.8 \mathrm{~m}^{2} / \mathrm{g}$ and a pore size of $1.5 \mathrm{~nm}$; this pore size value exceeding the range of pore size of MIL-53(Al), which usually between $0.7 \mathrm{~nm}$ and $1.3 \mathrm{~nm}$ [26]. The difference between the pore size values obtained in this study with those available in the literature possibly due to the solvent difference. In this study, we used a mixture of ethanol and water as the solvent, while most of the study used water as the solvent. The pore characteristic of MIL53( $\mathrm{Al})(\mathrm{ht})$ are listed in Table 2.

Table 2

Pore characteristic of MIL-53(Al)(ht).

\begin{tabular}{llll}
\hline Sample & $\begin{array}{l}\text { Surface area } \\
\mathrm{m}^{2} / \mathrm{g}\end{array}$ & $\begin{array}{l}\text { Total pore volume } \\
\mathrm{cm}^{3} / \mathrm{g}\end{array}$ & $\begin{array}{l}\text { Pore size } \\
\mathrm{nm}\end{array}$ \\
\hline MIL-53(Al)(ht) & 791.8 & 0.43 & 1.5 \\
\hline
\end{tabular}


Table 3

The concentration of cation and anion seawater in Balekambang beach.

\begin{tabular}{ll}
\hline Ion & Concentration $(\mathbf{m g} / \mathbf{L})$ \\
\hline $\mathrm{Cl}^{-}$ & $19200 \pm 214$ \\
$\mathrm{SO}_{4}^{2-}$ & $2461 \pm 53$ \\
$\mathrm{Na}^{+}$ & $10632 \pm 183$ \\
$\mathrm{~K}^{+}$ & $387 \pm 9.32$ \\
$\mathrm{Ca}^{2+}$ & $418 \pm 5.96$ \\
$\mathrm{Mg}^{2+}$ & $1278 \pm 35$ \\
Total & $34376 \pm 500.28$ \\
\hline
\end{tabular}

\subsection{The concentration of ions seawater in Balekambang beach}

The seawater composition collected from Balekambang beach contains several major anions (chloride, sulfate) and cations (sodium, potassium, calcium, and magnesium). The detail of concentration for each ion is summarized in Table 3. The seawater's $\mathrm{pH}$ is $7.8 \pm 1.04$; each concentration in the table is considered $C_{o}$ in this adsorption study.
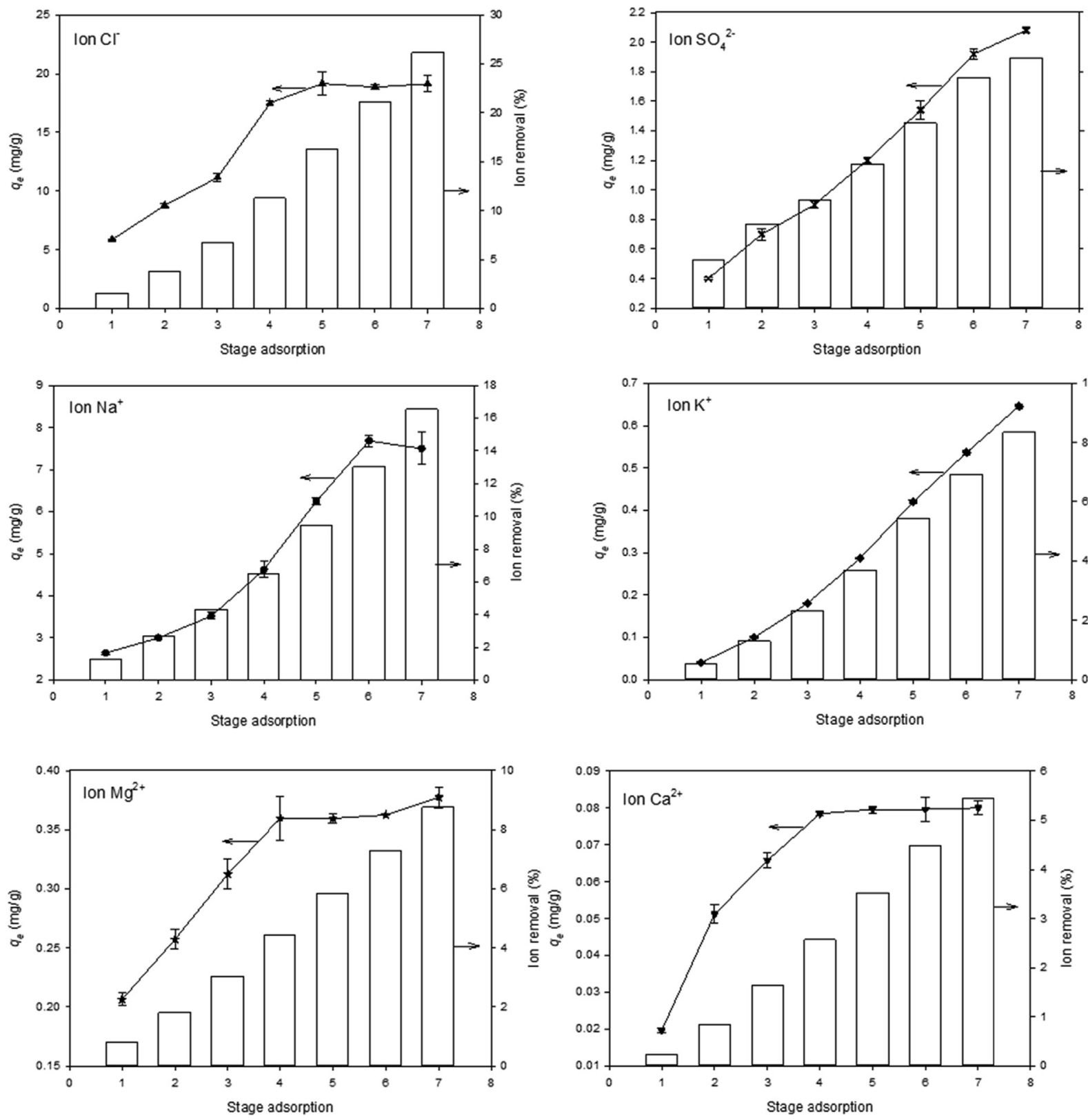

Fig. 2. The adsorption capacity of the ion at each stage and its removal efficiency. 


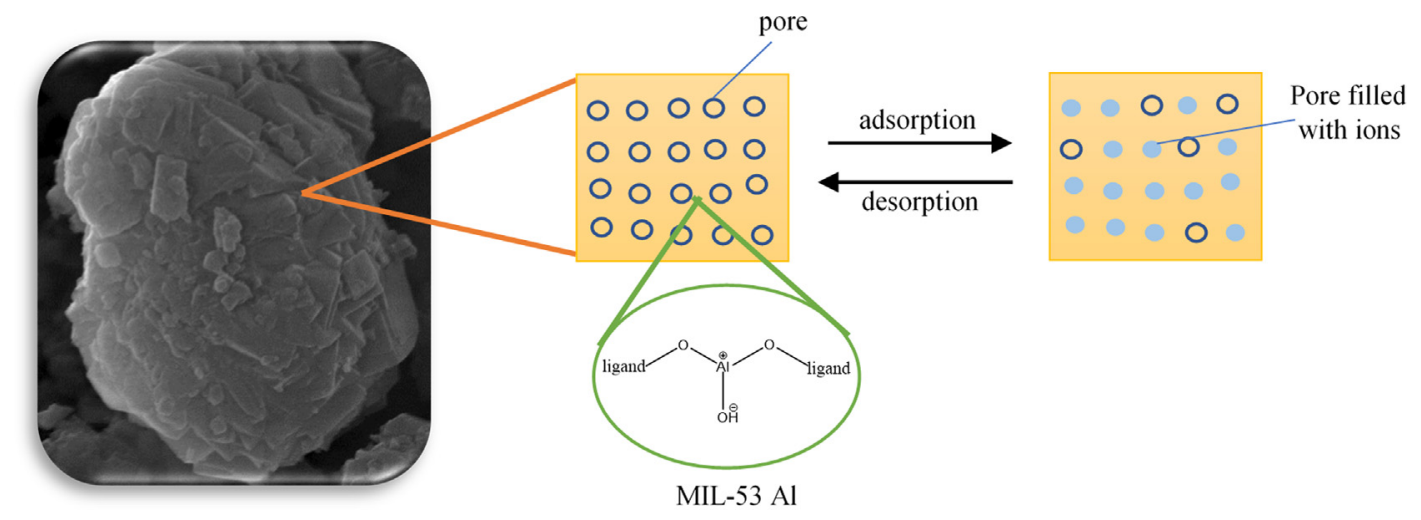

Fig. 3. Scheme of ion removal by adsorption using MIL-53(Al)(ht).

Table 4

Crystal radius, hydrated radius, and Gibbs hydration free energy of ions [36,37].

\begin{tabular}{llll}
\hline Ion & $\begin{array}{l}\text { Crystal radius } \\
(\mathbf{n m})\end{array}$ & $\begin{array}{l}\text { Hydrated radius } \\
(\mathbf{n m})\end{array}$ & $\begin{array}{l}\text { Gibbs hydration free energy } \\
(\mathbf{k J} / \mathbf{m o l})\end{array}$ \\
\hline $\mathrm{Na}^{+}$ & 0.95 & 0.35 & -365 \\
$\mathrm{~K}^{+}$ & 1.33 & 0.33 & -295 \\
$\mathrm{Mg}^{2+}$ & 0.65 & 0.42 & -1830 \\
$\mathrm{Ca}^{2+}$ & 0.99 & 0.41 & -1505 \\
$\mathrm{Cl}^{-}$ & 1.81 & 0.33 & -340 \\
$\mathrm{SO}_{4}^{2-}$ & 2.90 & 0.37 & -1080 \\
\hline
\end{tabular}

(ht) involved very complex phenomena. Many factors influence ions uptake by the sorbent, such as the concentration of ions, the interaction between ions and water, ions hydrated radius, etc.

As listed in Table 3, the most significant ion concentration in seawater is chloride; hence it has the highest possibility to occupy the active adsorption sites in the pore structure of MIL-53(Al)(ht) than other ions during the adsorption process. The removal of sulfate ions is not significant compared to chloride and sodium ions, which is less than $5 \%$ of removal efficiency. The removal efficiency of potassium ion is comparable with the divalent magnesium ion, removing $8.3 \%$ and $8.7 \%$, respectively, even though magnesium's adsorption capacity is three times higher than potassium ion, this is related to the concentration of both ions at the bulk solution. Even though the calcium ion has the lowest $q_{e}$ compared to the other ions, however, its removal efficiency (5.4\%) was higher than $\mathrm{SO}_{4}^{2-}$. The removal efficiency of ions corresponds to the initial concentration of each ion.

The ionic radius of the ions in seawater is summarized in Table 4. The adsorption of ions can be investigated through the ionic radius of the element; sulfate has the highest crystal radius as compared to other ions in seawater. In the solution, the ion is solvated and has spontaneously hydrated with the negative Gibbs energy. Nevertheless, this phenomenon must also be attributed to the diffusion of ions from bulk liquid to the adsorption site. The driving force which makes the adsorption process spontaneous is the mass transfer of each ion from the bulk solution through the boundary layer and finally adsorbed in the pore of MIL-53(Al)(ht) via intraparticle diffusion. The massive amount of $\mathrm{Cl}$ ion diffused into the pore is promoted by a small hydrated radius and higher bulk concentration than other ions. On the other hand, due to the highest crystal radius, $\mathrm{SO}_{4}^{2-}$ is less adsorbed to the pore structure of MIL-53( $\mathrm{Al})(\mathrm{ht})$ compared to other anions.

MOF in this study has comparable removal electrolytes efficiency to other materials such as composite graphene oxide-nano bentonite, carbon nanotube (CNT), and activated carbon. Banerjee et al. [12] studied the filtration of electrolytes using graphene oxide - nano bentonite, removing cations such as $\mathrm{Na}^{+}, \mathrm{K}^{+}, \mathrm{Mg}^{2+}$,

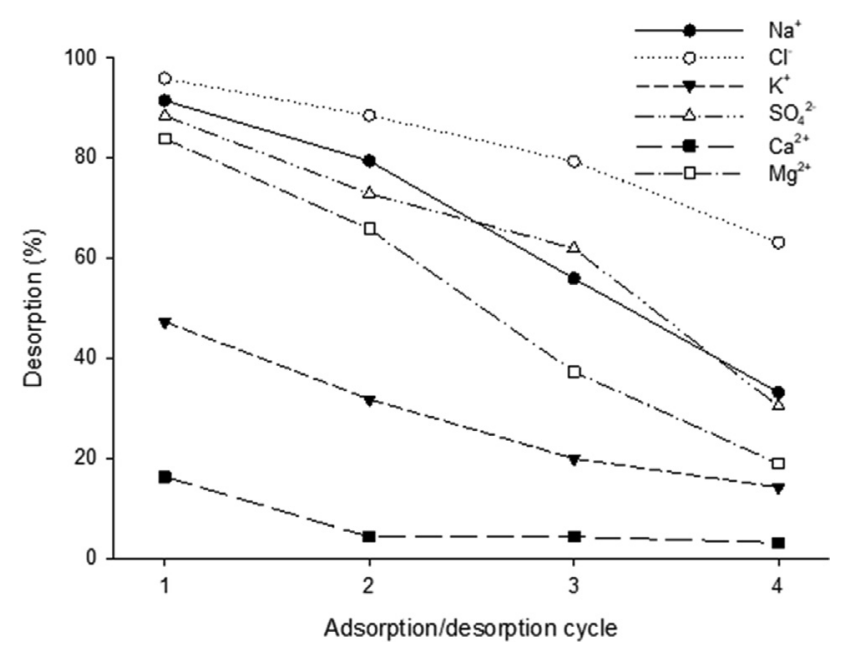

Fig. 4. Reusability of MIL-53(Al)(ht) for the removal of the ions from seawater.

and $\mathrm{Ca}^{2+}$ decreased significantly with the increasing initial concentration of $100 \mathrm{mg} / \mathrm{L}$. For the case of adsorption sodium ion, MIL-53 $(\mathrm{Al})(\mathrm{ht})$ has better removal with cumulative ion adsorption of $35.2 \mathrm{mg} / \mathrm{g}$ from initial concentration sodium of $10500 \mathrm{mg} / \mathrm{L}$, graphene oxide - nano bentonite can remove $\mathrm{Na}^{+}$around $57 \mathrm{mg} / \mathrm{L}$ from $100 \mathrm{mg} / \mathrm{L}$ by filtration [12]. While CNT has a high adsorption capacity for hardness ions such as calcium and magnesium ions, activated carbon has the same tendency as CNT [6,11]. Both carbon-based materials have preferences for divalent ions instead of monovalent ions [8].

\subsection{Regeneration of MIL-53(Al)(ht)}

The reusability of MIL-53(Al)(ht) was studied to see the industrial application prospect. The adsorption-desorption cycle results are depicted in Fig. 4; the release of ions into freshwater was high during the first cycle of the desorption process, more than $90 \%$ of adsorbed $\mathrm{Na}^{+}$and $\mathrm{Cl}^{-}$could be desorbed within $24 \mathrm{~h}$, while for $\mathrm{Mg}^{2+}$ and $\mathrm{SO}_{4}^{2-}$ ions was between 80 and $90 \%$. The amount of $\mathrm{K}^{+}$ ion desorbed was less than $50 \%$ for the first cycle. The desorption of $\mathrm{Ca}^{2+}$ is much lower than other ions; around $16 \%$ of $\mathrm{Ca}^{2+}$ could be regenerated during the first cycle and continue decreasing till almost no removal of calcium for the next cycle. The reusability of MIL-53(Al)(ht) constantly decreases for all ions after several cycles, indicating the industrial application's limitation. The summary of adsorption salt ion and reusability by several adsorbents is listed in Table 5. 
Table 5

The comparison of adsorbents for adsorption of salt and its reusability.

\begin{tabular}{llll}
\hline Adsorbent & Adsorption capacity $(\mathrm{mg} / \mathrm{g})$ & Reusability & Reference \\
\hline CNT & 141.2 & - & {$[6]$} \\
Carbon-based & 145.7 & - & {$[11]$} \\
$\quad$ materials & & & \\
MOF-Alg(Cu)/PVA & 80 & $26 \%^{\mathrm{a}}$ & {$[24]$} \\
MIL-53 (Al)(ht) & 147.7 & $33 \%^{\mathrm{b}}$ & This \\
& & & study \\
\hline
\end{tabular}

a in terms of ion removal rate at 4 th cycle.

b for ion sodium.

Lee and co-authors investigated the recyclability of the composite of MOF-Alginate $\mathrm{Cu}$. The adsorption of ions from synthetic seawater decreased abruptly after the first cycle with a difference of $20 \%$ ion removal rate and continued to diminish until 15\% at the 5 th cycle. The modification of MOF-Alginate copper with polyvinyl alcohol (PVA) has better reusability of adsorbent, proving the addition of PVA improved the ions removal rate of seawater up to 10 cycles of regeneration [25].

\section{Conclusion}

MIL-53(Al) was successfully synthesized with a mixture of ethanol and water solvent system, and it was further used as an adsorbent to remove ions from seawater. The crystallography of MOF is greatly affected by temperature. High-temperature activation causes crystal MIL-53( $\mathrm{Al})$ morphology to change from triclinic to orthorhombic crystal plane. The ion removal performance is best for chloride ions with $26 \%$ removal efficiency. The adsorption capacity of ions using MIL-53 followed the sequence $\mathrm{Cl}^{-}>\mathrm{Na}^{+}>$ $\mathrm{SO}_{4}^{2-}>\mathrm{Mg}^{2+}>\mathrm{K}^{+}>\mathrm{Ca}^{2+}$.

\section{CRediT authorship contribution statement}

Jindrayani Nyoo Putro: Conceptualization, Methodology, Visualization, Writing - original draft. Immanuel Joseph Ondang: Investigation, Validation, Formal analysis. Valentino Bervia Lunardi: Investigation, Validation, Formal analysis. Suryadi Ismadji: Writing - review \& editing, Funding acquisition, Supervision. Felycia Edi Soetaredjo: Writing - review \& editing, Funding acquisition, Supervision. Adriana Anteng Anggorowati: Investigation, Resources. Shella Permatasari Santoso: Writing - original draft. Jenni Lie: Investigation, Formal analysis. Chintya Gunarto: Investigation, Formal analysis.

\section{Declaration of Competing Interest}

The authors declare that they have no known competing financial interests or personal relationships that could have appeared to influence the work reported in this paper.

\section{References}

[1] USGS, Where is Earth's Water? https://www.usgs.gov/special-topic/waterscience-school/science/where-earths-water?qt-science_center_objects=0\#qtscience_center_objects (accessed November 2, 2020).

[2] X. Wang, K.C. Ng, Appl. Therm. Eng. 25 (2005) 2780-2789, https://doi.org/ 10.1016/j.applthermaleng.2005.02.011.
[3] M.W. Shahzad, M. Burhan, L. Ang, K.C. Ng, in: V.G. Gude (Ed.), Adsorption desalination-Principles, process design, and its hybrids for future sustainable desalination, Elsevier, 2018, pp. 3-34. doi:10.1016/B978-0-12-815818-0. 00001-1.

[4] K.C. Ng, X.L. Wang, L. Gao, A. Chakraborty, B.B. Saha, S. Koyama, A. Akisawa, Apparatus and Method for Desalination, WO 2006/121414 A1, 2006.

[5] O. Karnitz, L.V.A. Gurgel, L.F. Gil, Carbohydr. Polym. 79 (2010) 184-191, https://doi.org/10.1016/j.carbpol.2009.07.048.

[6] M.A. Tofighy, T. Mohammadi, Desalination 268 (2011) 208-213, https://doi. org/10.1016/j.desal.2010.10.028.

[7] A. Aghakhani, S.F. Mousavi, B. Mostafazadeh-Fard, Desalin. Water Treat. 51 (2013) 1928-1935, https://doi.org/10.1080/19443994.2012.714731.

[8] M.A. Alaei Shahmirzadi, S.S. Hosseini, J. Luo, I. Ortiz, J. Environ. Manage. 215 (2018) 324-344, https://doi.org/10.1016/j.jenvman.2018.03.040.

[9] A. Aghakhani, S.F. Mousavi, B. Mostafazadeh-Fard, R. Rostamian, M. Seraji, Desalination 275 (2011) 217-223, https://doi.org/10.1016/j.desal.2011.03.003.

[10] T.M. Sonqishe, Treatment of brines using commercial zeolites and zeolites synthesized from fly ash derivative, University of the Western Cape, 2008.

[11] A. Méndez, G. Gascó, Desalination 183 (2005) 249-255, https://doi.org/ 10.1016/j.desal.2005.03.038.

[12] P. Banerjee, A. Mukhopadhyay, P. Das, Desalination 451 (2019) 231-240, https://doi.org/10.1016/j.desal.2017.06.010.

[13] M.A.I. Ishak, K. Jumbri, S. Daud, M.B. Abdul Rahman, R. Abdul Wahab, H. Yamagishi, Y. Yamamoto, J. Hazard. Mater. 399 (2020) 123008, https://doi.org/ 10.1016/j.jhazmat.2020.123008.

[14] F. Ahmadijokani, R. Mohammadkhani, S. Ahmadipouya, A. Shokrgozar, M. Rezakazemi, H. Molavi, T.M. Aminabhavi, M. Arjmand, Chem. Eng. J. 399 (2020) 125346, https://doi.org/10.1016/j.cej.2020.125346.

[15] K. Yang, Y. Ban, A. Guo, M. Zhao, Y. Zhou, N. Cao, W. Yang, J. Memb. Sci. 611 (2020) 118419, https://doi.org/10.1016/j.memsci.2020.118419.

[16] X. Zhang, Z. Zong, X. Zhang, D. Zhang, Q. Luo, C. Bi, Y. Fan, Polyhedron. 191 (2020) 114816, https://doi.org/10.1016/j.poly.2020.114816.

[17] J. Zhang, P. Li, X. Zhang, X. Ma, B. Wang, ACS Appl Mater. Interfaces 12 (2020) 46057-46064, https://doi.org/10.1021/acsami.0c12693.

[18] D.V. Gonçalves, R.Q. Snurr, S.M.P. Lucena, Adsorption 25 (2019) 1633-1642, https://doi.org/10.1007/s10450-019-00165-8.

[19] M.W. Logan, S. Langevin, Z. Xia, Sci. Rep. 10 (2020) 1492, https://doi.org/ 10.1038/s41598-020-58405-9.

[20] E. Elsayed, R. AL-Dadah, S. Mahmoud, P.A. Anderson, A. Elsayed, P.G. Youssef Desalination. 406 (2017) 25-36. doi:10.1016/j.desal.2016.07.030.

[21] B. Han, A. Chakraborty, Energy Convers. Manag. 213 (2020) 112825, https:// doi.org/10.1016/j.enconman.2020.112825.

[22] R. Ou, H. Zhang, V.X. Truong, L. Zhang, H.M. Hegab, L. Han, J. Hou, X. Zhang, A. Deletic, L. Jiang, G.P. Simon, H. Wang, Nat. Sustain. (2020), https://doi.org/ 10.1038/s41893-020-0590-x.

[23] E. Wibowo, M. Rokhmat, Sutisna, Khairurrijal, M. Abdullah, Desalination 409 (2017) 146-156. doi: 10.1016/j.desal.2017.01.026.

[24] S.J. Lee, H.W. Lim, S.H. Park, Chemosphere. (2020) 128797, https://doi.org/ 10.1016/j.chemosphere.2020.128797.

[25] T. Wu, N. Prasetya, K. Li, J. Memb. Sci. 615 (2020), https://doi.org/10.1016/j. memsci.2020.118493.

[26] J. Canivet, J. Bonnefoy, C. Daniel, A. Legrand, B. Coasne, D. Farrusseng, New J. Chem. 38 (2014) 3102-3111, https://doi.org/10.1039/c4nj00076e.

[27] A.S. Edelstein, Nanomaterials, in: Encycl. Mater. Sci. Technol., Elsevier, 2001, pp. 5916-5927. doi:10.1016/B0-08-043152-6/01031-7.

[28] R.T. Sheen, H.L. Kahler, Direct titration of sulfates, Ind. Eng. Chem. Anal. Ed. 8 (1936) 127-130, https://doi.org/10.1021/ac50100a022.

[29] D. Himsl, D. Wallacher, M. Hartmann, Angew. Chemie - Int. Ed. 48 (2009) 4639-4642, https://doi.org/10.1002/anie.200806203.

[30] L. Feng, R. Chen, S. Hou, W. Chen, H. Huang, Y. Wang, Y. Wu, F. Li, J. Mater. Sci. 54 (2019) 6174-6185, https://doi.org/10.1007/s10853-018-03287-6.

[31] W.P. Mounfield, K.S. Walton, J. Colloid Interface Sci. 447 (2015) 33-39, https:// doi.org/10.1016/j.jcis.2015.01.027.

[32] T. Loiseau, C. Serre, C. Huguenard, G. Fink, F. Taulelle, M. Henry, T. Bataille, G. Férey, Chem. - A Eur. J. 10 (2004) 1373-1382, https://doi.org/10.1002/ chem.200305413.

[33] J.P.S. Mowat, S.R. Miller, J.M. Griffin, V.R. Seymour, S.E. Ashbrook, S.P. Thompson, D. Fairen-Jimenez, A.M. Banu, T. Düren, P.A. Wright, Inorg. Chem. 50 (2011) 10844-10858, https://doi.org/10.1021/ic201387d.

[34] P.L. Llewellyn, P. Horcajada, G. Maurin, T. Devic, N. Rosenbach, S. Bourrelly, C. Serre, D. Vincent, S. Loera-Serna, Y. Filinchuk, G. Férey, J. Am. Chem. Soc. 131 (2009) 13002-13008, https://doi.org/10.1021/ja902740r.

[35] D.D. Do, Adsorption analysis: equilibria and kinetics, Imperial College Press, London, 1998.

[36] Y. Marcus, Biophys. Chem. 51 (1994) 111-127, https://doi.org/10.1016/03014622(94)00051-4.

[37] E.R. Nightingale, J. Phys. Chem. 63 (1959) 1381-1387, https://doi.org/10.1021/ j150579a011. 